ScIDice

\section{Evaluation Of Clinical Success Of Preformed Aesthetic Crowns In Primary Molars - A Systematic Review}

Research Article

Subramanian $\mathrm{EMG}^{1 *}$, Aravind Kumar. $\mathrm{S}^{2}$, Kavitha Swaminathan ${ }^{3}$

${ }^{1}$ Professor, Department of Pediatric and Preventive Dentistry, Saveetha Dental college and Hospitals, Saveetha Institute of Medical and Technical Sciences, Saveetha University, Chennai - 600077, India.

${ }^{2}$ Professor, Department of Orthodontics and DentofacialOrthopaedics, Saveetha Dental college and Hospitals, Saveetha Institute of Medical and Technical Sciences, Saveetha University, Chennai - 600077, India.

${ }^{3}$ Associate Professor, Department of Pediatric and Preventive Dentistry, Sri Ramachandra Institute of Higher Education and Research, Sri Ramachandra University, Chennai- 600116, India.

\title{
Abstract
}

Background: Different aesthetic preformed crowns are emerging in the field to restore the decayed primary teeth as the benchmark restoration as Stainless steel crowns (SSC) do not satisfy the aesthetic needs of the patients.

Aim: The aim of the systematic review is to critically analyse the existing literature on clinical success of available aesthetic preformed crowns for primary molars.

Materials and Method: Detailed search strategies were carried out in Pubmed, PMC, Cochrane for identification of the studies that met the inclusion and exclusion criteria.

Results: A total of 5 articles were included for analysis. 4 studies compared Zirconia crowns and 1 study compared Figaro crowns to SSCs. All the 4 studies with zirconia crowns recorded 'high risk' of bias and the study with Figaro crowns recorded 'low risk' of bias.

Conclusion: Zirconia crowns (ZC) cannot be recommended as a replacement to SSCs in primary molars. On the other hand, more studies are required to declare Figaro crowns as a promising aesthetic replacement to SSC.

\section{Introduction}

Preservation of the decayed primary teeth, durability of the restoration and the parental satisfaction are the key factors for a successful paediatric dental practice. In primary dentition, full coverage restorations are indicated in large, multi surface carious lesions, teeth with bilateral proximal caries and after pulp therapy [1].

Stainless steel crowns (SSC) are the commonly used and preferred full coverage restorative option for treating severe carious lesions in the primary molars and maintaining them in position until the exfoliation because of its longevity when compared to other conventional restorations. Humphrey was the first to use
SSCs in pediatric population way back in 1950s and ever since it remains as the gold standard. The American Academy of Pediatric Dentistry also recommends SSC for posterior primary teeth with extensive carious lesion [2]. Despite numerous advantages of the SSCs, their metallic appearance is still an aesthetic concern for both the parents and the children [3-5]. In the modern era, aesthetic crowns to primary teeth is on increasing demand in pediatric practice.

The newly developed pre fabricated zirconia crowns (ZC) were introduced into pediatric dentistry in 1991 and currently remains as the only viable option the pedodontist are left with as aesthetic crowns, as the other options like the strip crowns open faced SSC, Preveneered SSC, polycarbonate crowns have been reported with

*Corresponding Author

Dr. Subramanian EMG,

Professor, Department of Pediatric and Preventive Dentistry, Saveetha Dental college and Hospitals, Saveetha Institute of Medical and Technical Sciences, Saveetha University, Chennai - 600077, India.

Tel: 9884125380

Email Id: subramanian@saveetha.com

Received: April 09, 2021

Accepted: May 02, 2021

Published: May 06, 2021

Citation: Subramanian EMG, Aravind Kumar. S, Kavitha Swaminathan. Evaluation Of Clinical Success Of Preformed Aesthetic Crowns In Primary Molars - A Systematic Review. Int J Dentistry Oral Sci. 2021;08(5):2362-2365. doi: http://dx.doi.org/10.19070/2377-8075-210000464

Copyright: Subramanian EMG $^{\circ} 2021$. This is an open-access article distributed under the terms of the Creative Commons Attribution License, which permits unrestricted use, distribution and reproduction in any medium, provided the original author and source are credited. 
several disadvantages [6, 7]. Zirconia is a successful restorative material in permanent teeth. However, its use in primary teeth started only recently and needs to be extensively studied [8, 9]. On the other hand, knowledge and studies are needed on other developing aesthetic preformed crowns for the practitioners and the parents to have an option to choose from.

The purpose of the present systematic review was to critically analyse the existing literature on the clinical success of available aesthetic preformed crowns for primary posterior teeth.

\section{Materials and Methods}

\section{Inclusion and Exclusion criteria}

Randomised control trials published in the last 5 years comparing the clinical success of aesthetic performed crowns and stainless steel crowns in primary molars were included in the study.

In-vitro studies, case reports and other observational studies were excluded from the analysis. Studies with Open face SSC and preveneered SSC were also excluded as it has been reported to have high failure rate $[10,11]$.

\section{Pico analysis}

Population - children requiring preformed crowns in primary molars

Intervention - aesthetic preformed crowns

Comparison - Stainless steel crowns

Outcome - Clinical success

\section{Search methods}

Detailed search strategies were carried out for identification of the studies that has to be included in the systematic review. Pubmed, PMC, Cochrane were the search engines used and hand search was also done.

\section{Assessment of the quality of the studies}

CONSORT guidelines were used for assessing the quality of the included studies. Data extraction for the general characteristics and outcome variables of the included studies was done. The risk of bias, including selection bias, detection bias and performance bias were assessed and was recorded as either high or low risk. Studies were recorded as 'low risk' of bias if all the criteria were met and 'high risk' if one or more criteria were not met.

\section{Results}

Selected key words and mesh terms were used in the search engines which yielded a total of 97 articles. Based on the preset inclusion and exclusion criteria 63 articles were selected. Hand searching yielded 3 articles. 61 Articles were eliminated after reading the title and abstracts. After thorough search 5 articles were included for analysis in the present systematic review. [Represented by Prisma flow chart Figure 1]. The studies included for the review are:

1. Pinar kinayTaran 2018 [12]
2. Kevin J DOnly, et al 2018 [13]

3. GihanAbuelniel 2018 [14]

4. Mebin George Mathew, et al 2020 [15]

5. Laila M El-Habashy 2020 [16]

The characteristics of the included study is depicted in Table 1 and the risk of bias assessment is tabulated in Table 2.

\section{Discussion}

The traditional benchmark restoration of the carious or pulp therapy treated primary molars with SSCs has been practiced for several decades but often fails to satisfy the parents and the children due to its metallic unaesthetic appearance. Hence, emerged the need for aesthetic preformed crowns. With this rising concept, a lot of aesthetic crowns have come into market and clinical trials are required to guide the practitioners to select the best suitable aesthetic crown. Hence, the present systematic review was conducted with the objective of assessing all the available randomised controlled clinical trials evaluating the clinical success with any aesthetic preformed crowns on primary molars.

In the present systematic review, 5 studies were included out of which 4 studies have compared SSC with ZC - NuSmile zirconia crowns(2studies), Ez ZC (1 study) and in another study the brand name was not mentioned. Figaro crowns were used in one study as preformed aesthetic crowns [16].

Except for the study done by Pinar et al, in all the other included studies the preformed aesthetic crown was compared to SSC. But in the study done by Pinar et al, the crowns were compared with the contralateral intact tooth as the primary objective of their study was to compare the gingival and oral hygiene status. However the clinical success of the crowns were also evaluated as a secondary output and hence were included into the analysis.

The articles included for the present systematic review reveals, there was no specific set criteria followed to assess the clinical success or the performance of the crowns. Crown retention, gingival health, stain resistance, marginal integrity and secondary caries at crown margins were the common factors evaluated for determining the clinical success of any crown. The other factors included were fracture, wear of the opposing tooth, colour match.

With regards to ZCs, the results of the clinical trials indicate that there was no difference in the clinical performance of both SSC and ZC till 12 months follow up. However, the statistical significance was not mentioned in the study done by Pinar et al. Also all the included studies comparing ZC with SSC showed high risk of bias. Random sequence generation was not mentioned in two studies $[12,14]$ and the method was not mentioned in another study [13]. None of the studies explained about allocation concealment. On the other hand, there is only one clinical trial conducted with Figaro crowns that recorded low risk of bias and the results of the study shows that Figaro crowns can be a promising option for aesthetic preformed crowns in primary molars but more studies are needed evaluating the wear and fracture resistant properties of Figaro crowns. Figaro crowns are nothing but preformed fibreglass crown for primary teeth introduced in the year 2018. Advantages of Figaro crowns over ZCs includes minimal tooth reduction similar to SSCs. 
Table 1. General characteristics of the selected articles.

\begin{tabular}{|c|c|c|c|c|c|}
\hline $\begin{array}{c}\text { AUTHOR } \\
\text { AND YEAR }\end{array}$ & Pinar KinayTaran 2018 & Kevin J Only 2018 & $\begin{array}{c}\text { GihanAbuelniel } \\
2018\end{array}$ & $\begin{array}{l}\text { Mebin George } \\
\text { Mathew } 2020\end{array}$ & $\begin{array}{c}\text { Laila M El Habashy } \\
2020\end{array}$ \\
\hline $\begin{array}{l}\text { STUDY DE- } \\
\text { SIGN }\end{array}$ & $\begin{array}{l}\text { Randomised controlled } \\
\text { clinical trial }\end{array}$ & $\begin{array}{l}\text { Randomised controlled } \\
\text { clinical trial }\end{array}$ & $\begin{array}{l}\text { Randomised con- } \\
\text { trolled clinical trial }\end{array}$ & $\begin{array}{l}\text { Randomised con- } \\
\text { trolled clinical trial }\end{array}$ & $\begin{array}{l}\text { Randomised controlled } \\
\text { clinical trial }\end{array}$ \\
\hline SAMPLE SIZE & 60 teeth & 100 teeth & 134 teeth & 60 teeth & 32 teeth \\
\hline AGE & $7.2+0.66$ & 3-7 years & \begin{tabular}{|l|}
$4.8+0.8-\mathrm{SSC}$ \\
$5.0+0.8-\mathrm{ZC}$
\end{tabular} & $6-8$ years & 4-6 years \\
\hline $\begin{array}{l}\text { CONTROL } \\
\text { GROUP }\end{array}$ & Contralateral intact molar & SSC & SSC & SSC & SSC \\
\hline TEST GROUP & \begin{tabular}{|l|} 
SSC \\
$\mathrm{ZC}$ \\
\end{tabular} & ZC [ NuSmile] & ZC [ NuSmile] & ZC [EZ Crown] & Figaro \\
\hline $\begin{array}{l}\text { VARIABLES } \\
\text { EVALUATED }\end{array}$ & \begin{tabular}{|l} 
OHI-S \\
PI \\
GI \\
Clinical success-
\end{tabular} & Clinical success & $\begin{array}{l}\text { OHI-S } \\
\text { GI } \\
\text { Clinical success } \\
\text { Radiographic success }\end{array}$ & $\begin{array}{l}\text { Clinical succes } \\
\text { Child and parental } \\
\text { satisfaction }\end{array}$ & Clinical success \\
\hline $\begin{array}{l}\text { OUTCOME } \\
\text { MEASURE- } \\
\text { MENT }\end{array}$ & $\begin{array}{l}\text { 1.Crown retention } \\
\text { 2.Gingival marginal } \\
\text { extension } \\
\text { 3.stain resistance } \\
\text { 4. Fracture }\end{array}$ & $\begin{array}{l}\text { 1. Gingival health } \\
\text { 2. Surface roughness } \\
\text { 3. Staining on the } \\
\text { crown surface } \\
\text { 4. Wear of opposing } \\
\text { tooth } \\
\text { 5. Color match } \\
\text { 6. Anatomic form } \\
\text { 7. Marginal integrity } \\
\text { 8. Marginal discoloura- } \\
\text { tion } \\
\text { 9. Proximal contact area } \\
\text { 10. Secondary caries at } \\
\text { crown margin }\end{array}$ & $\begin{array}{l}\text { 1. Length } \\
\text { 2. Position } \\
\text { 3. Polish } \\
\text { 4. Cement }\end{array}$ & $\begin{array}{l}\text { 1. Clinical success } \\
\text { criteria [ crown } \\
\text { retention and modi- } \\
\text { fied gingival index] }\end{array}$ & $\begin{array}{l}\text { 1. Crown retention } \\
\text { 2. Marginal integrity } \\
\text { 3. Recurrent caries } \\
\text { 4. Gingival index } \\
\text { 5. Plaque index } \\
\text { 6. Colour change }\end{array}$ \\
\hline $\begin{array}{l}\text { CLINICAL } \\
\text { SUCCESS }\end{array}$ & $\begin{array}{l}\text { 1. Crown retention:ZCs- } \\
\text { 2 decemented, SSC- } \\
\text { 100\% crown retention } \\
\text { 2. Staining: ZC- mild } \\
\text { staining in 1 Zc @3 } \\
\text { month } \\
\text { 3. Fracture: } \\
\text { ZC - 1@12 months } \\
\text { - statistical significance - } \\
\text { not mentioned }\end{array}$ & $\begin{array}{l}\text { No statistically signifi- } \\
\text { cant difference in the } \\
\text { clinical success of both } \\
\text { ZC and SSC@6,12, } \\
24 \text { months }\end{array}$ & $\begin{array}{l}75.8 \% \text { - SSC } \\
80.8 \% \text { - ZC } \\
\text { No statistically } \\
\text { significant difference } \\
\text { in the clinical success } \\
\text { of both ZC and SSC } \\
\text { @ } 12 \text { months }\end{array}$ & $\begin{array}{l}100 \% \text { success rate } \\
\text { for both SSC and } \\
\text { ZC. }\end{array}$ & $\begin{array}{l}\text { 1. No statistically } \\
\text { significant difference } \\
\text { in the retention of the } \\
\text { crowns at } 3 \text { months but } \\
\text { at } 6 \text { months there was } \\
\text { a difference in Figaro } \\
\text { crown group. } \\
\text { 2. No statistically } \\
\text { significant difference } \\
\text { with respect to recur- } \\
\text { rent caries, gingival and } \\
\text { plaque index. } \\
\text { 3. Statistically sig- } \\
\text { nificant change in the } \\
\text { colour was noted in } \\
\text { Figaro crowns }\end{array}$ \\
\hline
\end{tabular}

Table 2. Risk of bias of the included articles.

\begin{tabular}{|c|c|c|c|c|c|c|c|}
\hline SNO & STUDY & $\begin{array}{c}\text { SAMPLE SIZE } \\
\text { DETERMINA- } \\
\text { TION }\end{array}$ & $\begin{array}{c}\text { RANDOM } \\
\text { SEQUENCE } \\
\text { GENERATION }\end{array}$ & $\begin{array}{c}\text { ALLOCATION } \\
\text { CONCEALE- } \\
\text { MENT }\end{array}$ & $\begin{array}{c}\text { BLINDING OF } \\
\text { THE PARTICI- } \\
\text { PANTS }\end{array}$ & $\begin{array}{c}\text { BLINDING OF } \\
\text { THE OUTCOME } \\
\text { ASSESSOR }\end{array}$ & $\begin{array}{c}\text { RISK OF } \\
\text { BIAS }\end{array}$ \\
\hline 1 & $\begin{array}{c}\text { Pinar Kinay- } \\
\text { Taran 2018 }\end{array}$ & Good & Poor & Poor & Not applicable & Not applicable & HIGH \\
\hline 2 & $\begin{array}{c}\text { Kevin J Only } \\
2018\end{array}$ & Good & Fair & Poor & Not applicable & Not applicable & HIGH \\
\hline 3 & $\begin{array}{c}\text { GihanAbuel- } \\
\text { niel 2018 }\end{array}$ & Fair & Poor & Poor & Not applicable & Not applicable & HIGH \\
\hline 4 & $\begin{array}{c}\text { Mebin George } \\
\text { Mathew 2020 }\end{array}$ & Good & Good & Poor & Not applicable & Not applicable & HIGH \\
\hline 5 & $\begin{array}{c}\text { Laila M El } \\
\text { Habashy 2020 }\end{array}$ & Good & Good & Good & Not applicable & Not applicable & LOW \\
\hline
\end{tabular}


Blinding was not applicable in any of the included studies to the participant, operator and the assessor as the colours of the crowns cannot be masked. Hence, it was marked not applicable and was not included as a criteria for assessing the risk of bias of the included studies.

Meta analysis was not possible in the present systematic review as the outcome variables and the comparisons of the included studies were different and hence aesthetic full coverage recommendations to posterior teeth cannot be implemented. Also it is the duty of the practitioner to inform the parents on low level proof supporting preformed aesthetic crowns in primary molars.

\section{Conclusion}

The overall high risk of bias in RCTs comparing Zirconia crowns to SSC does not support in recommending ZCs as an effective replacement to SSCs in primary molars. On the other hand, more Randomised controlled trials with consistent preset clinical criteria is required to declare Figaro crowns as a promising aesthetic replacement to SSC.

\section{Acknowledgment}

Damascus university has funded this study.

\section{References}

[1]. American Academy of Pediatric Dentistry reference manual 2007-2008. Pediatr Dent. 2007-2008;29(7 Suppl):1-271. PubmedPMID: 18268823.

[2]. American Academy of Pediatric Dentistry. Guideline on restorative dentistry. ClinPractGuidel 2014;37:15-16.

[3]. Bell SJ, Morgan AG, Marshman Z, Rodd HD. Child and parental acceptance of preformed metal crowns. Eur Arch Paediatr Dent. 2010
Oct;11(5):218-24. PubmedPMID: 20932394.

[4]. Champagne C, Waggoner W, Ditmyer M, Casamassimo PS, MacLean J. Parental satisfaction with preveneered stainless steel crowns for primary anterior teeth. Pediatr Dent. 2007 Nov-Dec;29(6):465-9. Erratum in: Pediatr Dent. 2008 Jan-Feb;30(1):8. MacLean, Jeanette [added]. PubmedPMID: 18254415.

[5]. Shah PV, Lee JY, Wright JT. Clinical success and parental satisfaction with anterior preveneered primary stainless steel crowns. Pediatr Dent. 2004 SepOct;26(5):391-5. PubmedPMID: 15460292.

[6]. Ram D, Fuks AB, Eidelman E. Long-term clinical performance of esthetic primary molar crowns. Pediatr Dent. 2003 Nov-Dec;25(6):582-4. PubmedPMID: 14733474.

[7]. Helpin ML. The open-face steel crown restoration in children. ASDC J Dent Child. 1983 Jan-Feb;50(1):34-8. PubmedPMID: 6338070.

[8]. Ashima G, Sarabjot KB, Gauba K, Mittal HC. Zirconia crowns for rehabilitation of decayed primary incisors: an esthetic alternative. J ClinPediatr Dent. 2014 Fall;39(1):18-22.PubmedPMID: 25631720.

[9]. PlanellsdelPozo P, Fuks AB. Zirconia crowns--an esthetic and resistant restorative alternative for ECC affected primary teeth. J ClinPediatr Dent. 2014 Spring;38(3):193-5. PubmedPMID: 25095311.

[10]. Ram D, Fuks AB, Eidelman E. Long-term clinical performance of esthetic primary molar crowns. Pediatr Dent. 2003 Nov-Dec;25(6):582-4. PubmedPMID: 14733474.

[11]. Shah PV, Lee JY, Wright JT. Clinical success and parental satisfaction with anterior preveneered primary stainless steel crowns. Pediatr Dent. 2004 SepOct;26(5):391-5. PubmedPMID: 15460292.

[12]. Taran PK, Kaya MS. A Comparison of Periodontal Health in Primary Molars Restored with Prefabricated Stainless Steel and Zirconia Crowns. Pediatr Dent. 2018 Sep 15;40(5):334-339. PubmedPMID: 30355428.

[13]. Donly KJ, Sasa I, Contreras CI, Mendez MJC. Prospective Randomized Clinical Trial of Primary Molar Crowns: 24-Month Results. Pediatr Dent. 2018 Jul 15;40(4):253-258. PubmedPMID: 30345963.

[14]. Abuelniel G, Eltawil S. Clinical and Radiographic Evaluation of Stainless Steel versus Zirconia Crowns on Primary Molars: Randomized Controlled Trial. Egyptian Dental Journal. 2018 Apr 1;64(2-April (Orthodontics, Pediatric \& Preventive Dentistry)):977-89.

[15]. Mathew MG, Roopa KB, Soni AJ, Khan MM, Kauser A. Evaluation of Clinical Success, Parental and Child Satisfaction of Stainless Steel Crowns and Zirconia Crowns in Primary Molars. J Family Med Prim Care. 2020 Mar 26;9(3):1418-1423. PubmedPMID: 32509626.

[16]. El-Habashy LM, El Meligy OA. Fiberglass crowns versus preformed metal crowns in pulpotomized primary molars: a randomized controlled clinical trial. Quintessence Int. 2020;51(10):844-852. PubmedPMID: 32901239. 